\title{
Comparative evaluation of surgical stress of laparoscopically assisted vaginal radical hysterectomy and lymphadenectomy and laparotomy for early-stage cervical cancer
}

\author{
CAI-YING HOU ${ }^{1}$, XIU-LI LI ${ }^{1}$, FENG JIANG $^{2}$, RONG JIE GONG ${ }^{3}$, XIN YU GUO $^{1}$ and YUAN-QING YAO ${ }^{1}$ \\ ${ }^{1}$ Department of Gynecology and Obstetrics, PLA General Hospital, Beijing 100853; \\ ${ }^{2}$ Department of Gynecology and Obstetrics, Tangdu Hospital, Fourth Military Medical University, Xi'an 710038; \\ ${ }^{3}$ Out-Patient Department of the Second Artillery Corps, Beijing 100045, P.R. China
}

Received December 21, 2010; Accepted May 4, 2011

DOI: $10.3892 / 01.2011 .311$

\begin{abstract}
The aim of this study was to objectively evaluate the benefits of laparoscopically assisted vaginal radical hysterectomy and lymphadenectomy for early-stage cervical cancer. Clinical data were prospectively collected from patients with IA-IIB cervical cancer who underwent laparoscopically assisted vaginal radical hysterectomy $(\mathrm{n} 1=33)$ and laparotomy $(\mathrm{n} 2=30)$. Peripheral blood samples were obtained prior to surgery and at 1 and $2 \mathrm{~h}$ into the operation, as well as on days 1, 4 and 7 following surgery to measure serum interleukin-6, C-reaction protein and cortisol. Results showed that there was no conversion to laparotomy in the laparoscopy group. The average blood loss was $317.23 \pm 217.20 \mathrm{ml}$ (laparoscopy group) and $872.58 \pm 693.16 \mathrm{ml}$ (laparotomy group). No significant difference was found in the number of resected pelvic lymph nodes $(19.74 \pm 7.43$ in the laparoscopy group and $20.35 \pm 6.62$ in the laparotomy group). At days 1 and 7 after surgery, the serum IL-6 level was significantly different in the laparoscopy and laparotomy groups (day 1: laparoscopy group $17.14 \pm 16.53 \mathrm{pg} / \mathrm{ml}$ and laparotomy group $34.32 \pm 20.97 \mathrm{pg} / \mathrm{ml}$, $\mathrm{p}=0.001$; day 7 : laparoscopy group $6.7 \pm 7.21 \mathrm{pg} / \mathrm{ml}$ and laparotomy group $17.54 \pm 16.47 \mathrm{pg} / \mathrm{ml}, \mathrm{p}=0.001$ ). The serum CRP level was significantly different at days 1 and 7 after the operation (day 1: laparoscopy group 7024.72 $\pm 949.12 \mathrm{ng} / \mathrm{ml}$ and laparotomy group $7586.61 \pm 869.42 \mathrm{ng} / \mathrm{ml}, \mathrm{p}=0.018$; day 7 : laparoscopy group $4357.71 \pm 2108.85 \mathrm{ng} / \mathrm{ml}$ and laparotomy group $6967.96 \pm 995.02 \mathrm{ng} / \mathrm{ml}, \mathrm{p}<0.001)$. A significant difference was noted in the serum cortisol level at day 4 after the operation $(122.29 \pm 65.17 \mathrm{ng} / \mathrm{ml}$ in the laparoscopy group and $186.76 \pm 68.61 \mathrm{ng} / \mathrm{ml}$ in the laparotomy group, $\mathrm{p}<0.001)$. In
\end{abstract}

Correspondence to: Dr Yuan-Qing Yao, Department of Obstetrics and Gynecology, PLA General Hospital, Fu Xing St, Beijing 100853, P.R. China

E-mail: yqyao@hotmail.com

Key words: cervical cancer, laparoscopic assisted vaginal hysterectomy, laparotomy, CRP, IL-6, Cristol conclusion, the differences in clinical data and the various parameters pertinent to surgical stress evaluated in this study suggest that laparoscopic surgery for cervical cancer causes less postoperative stress than conventional open surgery.

\section{Introduction}

Laparoscopy has become an attractive approach in surgical treatment in gynecologic oncology. Various studies have been published demonstrating the feasibility and safety of this technique. Its main advantages over laparotomy are less blood loss and a shorter length of postoperative hospitalization and earlier recovery, with a substantial equivalence in terms of the number of lymph nodes removed. From these advantages, laparoscopy is considered to be minimally invasive surgery. However, few authors have objectively evaluated how invasive these two methods of surgery are.

This prospective clinical study was performed to evaluate whether the trauma is less in laparoscopic surgery compared to laparotomy when dealing with cervical cancer. The effects of proinflammatory cytokine interleukin-6 (IL-6), C-reactive protein (CRP) and cortisol were analyzed for the two groups. This study, therefore, evaluates the effects of laparoscopic and conventional cervical surgery on specific and non-specific responses following major abdominal surgery.

In this study, we aimed to evaluate the extent of surgical trauma after laparoscopic and open radical hysterectomy and lymphadenectomy by comparing the clinical data and examining serum values of IL-6, CRP and cortisol to clarify whether patients benefit from the laparoscopic technique and whether it is a minimally invasive approach.

\section{Materials and methods}

Patient groups. Data were prospectively collected and recorded from 63 patients who underwent laparoscopic radical hysterectomy with lymphadenectomy and conversional open surgery for stage IA-IIB cervical cancer between May 2009 and July 2010. Age, body mass index, site and type of malignancy, and the International Federation of Gynecology and Obstetrics (FIGO) staging were noted. Surgery was performed 
Table I. Patient characteristics.

\begin{tabular}{lcc}
\hline & Laparoscopy $(\mathrm{n} 1=33)$ & Laparotomy (n2=30) \\
\hline Mean age, years (range) & $47.55(27-63)$ & $44.94(27-79)$ \\
Median BMI, $\mathrm{kg} / \mathrm{m}^{2}$ (range) & $23.64 \pm 2.72(18.29-30.85)$ & $22.72 \pm 2.92(16.8-30.48)$ \\
Stage & 4 & 2 \\
IA & 10 & 10 \\
IB & 15 & 14 \\
IIA & 4 & 4 \\
IIB & 25 & 22 \\
Histology & 6 & 6 \\
Squamous & 1 & 1 \\
Adenocarcinoma & Neuroendocrine carcinoma & Clear-cell carcinoma \\
Adenosquamous & & \\
Other & & \\
\hline BMI, body mass index. & & \\
\hline
\end{tabular}

Table II. Surgical data.

\begin{tabular}{lcr}
\hline & Laparoscopy (n1=33) & Laparotomy (n2=30) \\
\hline Lymph nodes resected & $19.74 \pm 7.43(5-38)$ & $20.35 \pm 6.62(9-33)$ \\
Duration, min (range) & $202 \pm 39(135-258)$ & $128 \pm 28(117-149)$ \\
Blood loss, ml (range) & $317.23 \pm 217.20(100-1000)$ & $872.58 \pm 693.16(200-3400)$ \\
Blood transfusion rate, $\%$ & 27.27 & 83.33 \\
Postoperative exhaust, days (range) & $1.83 \pm 0.43(1-3)$ & $2.77 \pm 0.67(1-4)$ \\
Hospital stay, days (range) & $19.4 \pm 5.15(9-36)$ & $22.9 \pm 10.05(13-68)$ \\
Postoperative hospital stay (range) & $11.72 \pm 3.62(5-23)$ & $16.42 \pm 10.04(10-63)$
\end{tabular}

at the Department of Gynecologic Oncology at the PLA General Hospital in Beijing, China. Inclusion criteria were: good general condition, stage IA-IIB cancer, and no evidence of lymph node metastases in imaging study (MRI and/or CT and/or PET). A total of 9 patients accepted preoperative intra-arterial chemotherapy. Patients were staged based on clinical evaluation according to the most recent FIGO clinical staging system.

The patients were informed of risks and possible complications of the surgical procedure and provided written informed consent. The patients received a bowel preparation and a 3-dose antibiotic prophylaxis prior to the operation.

Laparoscopic surgery was performed as a laparoscopically assisted procedure as described by other authors (1-3). To minimize the risk of port site metastases, the lymph nodes were placed into a bag and removed vaginally at the end of the intervention.

Initially, ureteral bilateral stents were placed preoperatively, in order to facilitate laparoscopic ureteral manipulation and minimize the risk of ureteral damage. They were removed at the first clinical control 30 days after surgery.

The urethral catheter was removed 2 days after the intervention. Intermittent catheterization was performed three times a day until residual urine volumes of $<50 \mathrm{ml}$ were obtained at least twice.

Survival and outcomes. Follow-up consisted of a pelvic examination every 3 months during the first two years, three times a year from the third to the fifth year, and annually thereafter. TCT and HPV tests were performed every year. X-ray and CT were performed when necessary.

Samples and assays. Peripheral venous blood samples were collected in EDTA collection tubes to be analyzed for cytokines IL-6, CRP and cortisol before surgery, $1 \mathrm{~h}$ and $2 \mathrm{~h}$ into surgery, and 1, 4 and 7 days after surgery. The samples were centrifuged at $4500 \mathrm{~g}$ for $10 \mathrm{~min}$. Serum samples were separated into PE tubes and stored at $-80^{\circ} \mathrm{C}$ until analysis. Serum IL-6 and CRP were measured using commercially available sandwich enzyme-linked immunosorbent assays (ELISA kits) (R\&D Systems, Minneapolis, MN, USA). The minimum sensitivity of the assays was $0.70 \mathrm{pg} / \mathrm{ml}$ for IL-6 and $0.01 \mathrm{ng} / \mathrm{ml}$ for CRP. The concentration of cortisol in serum was measured using a radioimmunoassay (RIA) kit (The North Biological Technology Co., Ltd., Beijing, China) with a minimum detectable level of $2 \mathrm{ng} / \mathrm{ml}$. 
Statistical analysis. Results are expressed as the means \pm SEM. Statistical differences within each group were determined by repeated measures of analysis of variance (ANOVA) on ranks, followed by the Student Newman-Keuls test. The groups were compared statistically using the Mann-Whitney rank sum test. $\mathrm{P}<0.05$ was considered to be statistically significant.

\section{Results}

\section{Patient and surgical data}

Patient data. Between May 2009 and July 2010, 63 patients underwent laparoscopic radical hysterectomy and pelvic lymphadenectomy for stage IA-IIB early cervical cancer. Surgery was performed at the Department of Gynecologic Oncology of the PLA General Hospital, Beijing, China. All 63 patients were diagnosed by vaginoscopic biopsy. There was no patient conversion to laparotomy in the laparoscopy group. The clinical and pathological characteristics are summarized in Table I.

No significant difference was noted in age between the laparoscopy group (47.55 years old) and the laparotomy group (44.94 years old, $\mathrm{p}=0.254$ ). Median BMI was $23.64 \mathrm{~kg} / \mathrm{m}^{2}$ and $22.72 \mathrm{~kg} / \mathrm{m}^{2}$, respectively $(\mathrm{p}=0.159)$. The predominant histotype was squamous (25 patients in the laparoscopy group and 22 patients in the laparotomy group), followed by adenocarcinoma (6 patients in each group), adenosquamous (1 patient in each group) and other histotypes (neuroendocrine carcinoma in 1 patient in the laparoscopy group and clear-cell carcinoma in 1 patient in the laparotomy group). None of the patients showed MRI or CT evidence of lymph node involvement.

Surgical data. The surgical data are summarized in Table II. Operative time for the laparoscopy group was $202 \pm 39 \mathrm{~min}$, which differed from the laparotomy group $(128 \pm 28 \mathrm{~min}$, $\mathrm{p}=0.05$ ). The estimated blood loss for patients undergoing laparoscopy was $317.23 \pm 217.20 \mathrm{ml}$. This blood loss was significantly less than in the laparotomy group $(872.58 \pm 693.16 \mathrm{ml}$, $\mathrm{p}<0.0001$ ). Laparoscopy patients had an average of 19.74 nodes retrieved as compared to 20.35 nodes retrieved in laparotomy patients. The differences were not significant $(\mathrm{p}=0.712)$. The mean length of postoperative hospital stay was 11.72 days in the laparoscopy group and 16.42 days in the laparotomy group $(\mathrm{p}=0.004)$.

\section{Serum cytokine concentrations}

Time course of IL-6 serum levels in laparoscopic and conventional open surgery. Both laparoscopic and conventional open surgery caused a significant increase in serum IL-6 levels 1 and 7 days after the operation (Fig. 1) and the maximum increase was found 1 day after the operation. A comparison between the laparoscopy and open surgery groups showed a significantly less pronounced increase of IL-6 in the laparoscopy group, which was most evident 1 and 7 days after the operation $(\mathrm{p}<0.001)$. Results noted were: pre-operation: laparoscopy $0.41 \pm 0.85 \mathrm{pg} / \mathrm{ml}$ and laparotomy $0.40 \pm 1.24 \mathrm{pg} / \mathrm{ml}$, $\mathrm{p}=0.983$; day 1 : laparoscopy $17.14 \pm 16.53 \mathrm{pg} / \mathrm{ml}$ and laparotomy $34.32 \pm 20.97 \mathrm{pg} / \mathrm{ml}, \mathrm{p}<0.001$; day 4: laparoscopy $15.89 \pm 31.47 \mathrm{pg} / \mathrm{ml}$ and laparotomy $23.34 \pm 29.03 \mathrm{pg} / \mathrm{ml}$, $\mathrm{p}=0.334$; day 7 : laparoscopy $6.7 \pm 7.21 \mathrm{pg} / \mathrm{ml}$ and laparotomy $17.54 \pm 16.47 \mathrm{pg} / \mathrm{ml}, \mathrm{p}<0.001$.

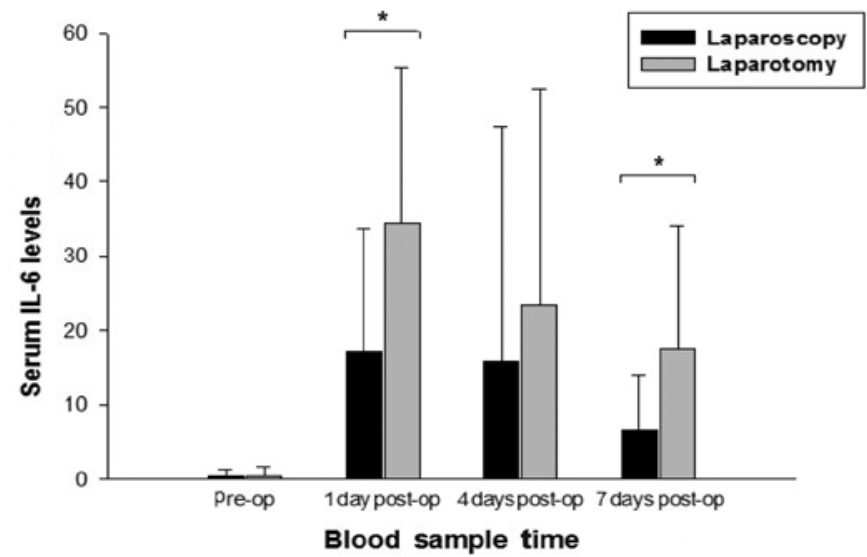

Figure 1. Circulating interleukin-6 (IL-6) levels as determined by enzymelinked immunosorbent assays in patients with cervical cancer with open surgery. ${ }^{*} \mathrm{P}<0.001$ for laparoscopic vs. open surgery.

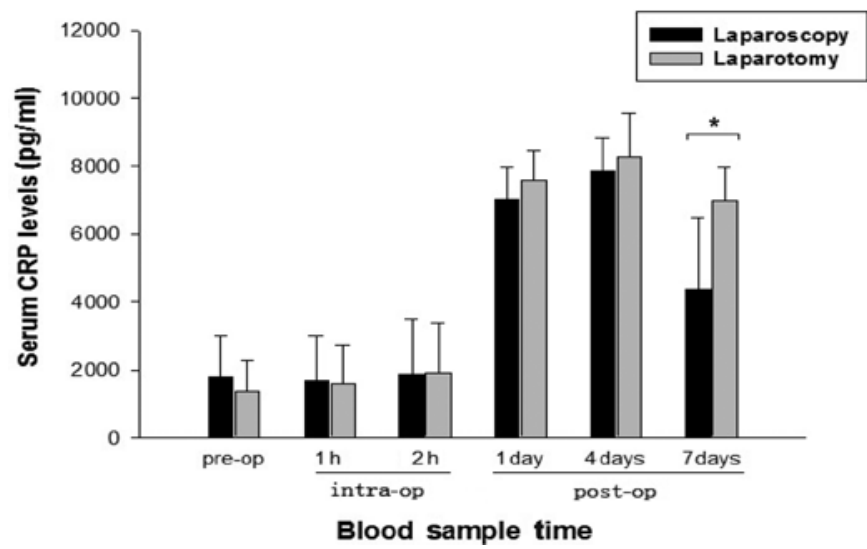

Figure 2. Circulating C-reactive protein (CRP) levels as determined by enzyme-linked immunosorbent assays in patients with cervical cancer treated with open and laparoscopic surgery. " $\mathrm{P}<0.001$ for laparoscopic vs. open surgery.

Time course of C-reactive protein serum levels in lapascopic and conventional open surgery. Daily analysis of serum CRP values over the 7 days following surgery showed a significant increase after the laparoscopic and open procedures (Fig. 2). This increase was significantly higher at days 1 and 7 in conventional surgery patients compared with laparoscopy patients ( $\mathrm{p}=0.018$ and $\mathrm{p}<0.001$, respectively). Results noted were: pre-operation: laparoscopy $1796.30 \pm 1221.30 \mathrm{ng} / \mathrm{ml}$ and laparotomy $1365.30 \pm 929.57 \mathrm{ng} / \mathrm{ml}, \mathrm{p}=0.123$; $1 \mathrm{~h}$ : laparoscopy $1684.64 \pm 1330.09 \mathrm{ng} / \mathrm{ml}$ and laparotomy $1580.64 \pm 1126.57 \mathrm{ng} /$ $\mathrm{ml}, \mathrm{p}=0.74 ; 2 \mathrm{~h}$ : laparoscopy $1889.53 \pm 1584.08 \mathrm{ng} / \mathrm{ml}$ and laparotomy $1905.52 \pm 1478.04 \mathrm{ng} / \mathrm{ml}, \mathrm{p}=0.967$; day 1 : laparoscopy $7024.72 \pm 949.12 \mathrm{ng} / \mathrm{ml}$ and laparotomy $7586.61 \pm 869.42 \mathrm{ng} / \mathrm{ml}$, $\mathrm{p}=0.018$; day 4: laparoscopy $7855.67 \pm 975.20 \mathrm{ng} / \mathrm{ml}$ and laparotomy $8265.33 \pm 1310.99 \mathrm{ng} / \mathrm{ml}, \mathrm{p}=0.162$; day 7 : laparoscopy $4357.71 \pm 2108.85 \mathrm{ng} / \mathrm{ml}$ and laparotomy $6967.96 \pm 995.02 \mathrm{ng} /$ $\mathrm{ml}, \mathrm{p}<0.001$.

Time course of the cortisol serum levels in laparoscopic and conventional open surgery. A significant increase of circulating cortisol levels was observed after both laparoscopic 


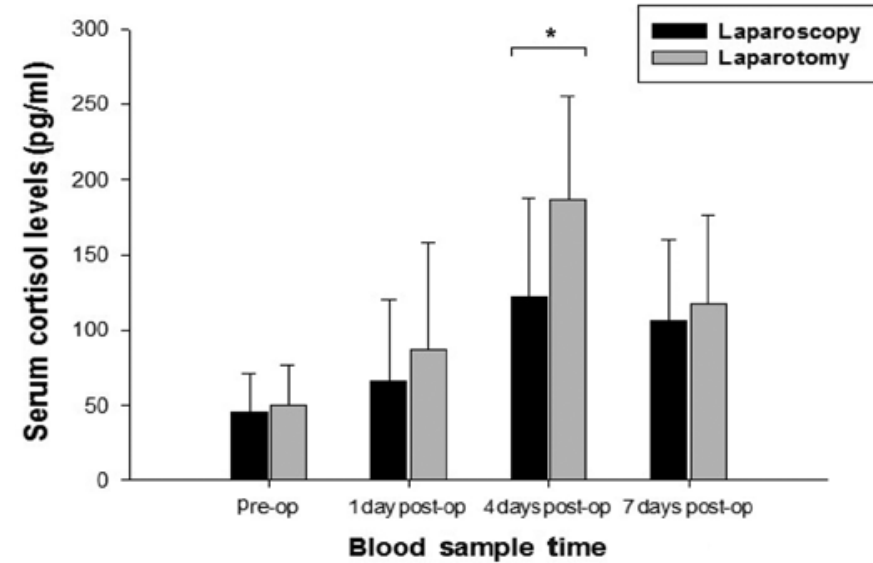

Figure 3. Circulating cortisol levels as determined by radioimmunoasssay in patients with cervical cancer treated with open and laparoscopic surgery. ${ }^{*} \mathrm{P}<0.001$ for laparoscopic vs open surgery.

and open surgery (Fig. 3). This increase was significantly higher at 4 days after the operation in conventional surgery patients compared with laparoscopy patients $(\mathrm{p}<0.001)$. Pre-operation: laparoscopy $45.15 \pm 26.53 \mathrm{ng} / \mathrm{ml}$ and laparotomy $49.63 \pm 27.42 \mathrm{ng} / \mathrm{ml}, \mathrm{p}=0.513$; day 1 : laparoscopy $66.13 \pm 54.15 \mathrm{ng} / \mathrm{ml}$ and laparotomy $86.96 \pm 70.85 \mathrm{ng} / \mathrm{ml}$, $\mathrm{p}=0.192$; day 4: laparoscopy $122.29 \pm 65.17 \mathrm{ng} / \mathrm{ml}$ and laparotomy $186.76 \pm 68.61 \mathrm{ng} / \mathrm{ml}, \mathrm{p}<0.001$; day 7: laparoscopy $106.50 \pm 53.31 \mathrm{ng} / \mathrm{ml}$ and laparotomy $116.87 \pm 59.49 \mathrm{ng} / \mathrm{ml}$, $\mathrm{p}=0.468$.

\section{Discussion}

Research has shown that laparoscopic radical hysterectomy is feasible and safe and induces less trauma due to less intraoperative bleeding, less postoperative pain, a shorter period of recovery and a shorter hospital stay, while the number of lymph nodes removed was almost equal to that shown in conventional open surgery (4-14). Laparoscopically assisted vaginal hysterectomy has become the preferred approach for cervical cancer treatment. Experimental studies have shown that laparoscopic surgery has a low impact on cancer growth (15-16). Mounting evidence shows that cervical cancer recurrence and survival rates after laparoscopic surgery are comparable with those observed after laparotomy, despite the results of prospective randomized trials. Concomitantly, laparoscopy patients have better cosmetic results and quality of life.

In our study, the mean blood loss was found to be $317 \mathrm{ml}$ (range 100-1000) in the laparoscopy group and $872 \mathrm{ml}$ (200-3400) in the laparotomy group; a significant difference $(p<0.0001)$. The mean operative time was $202 \mathrm{~min}$ (range 135-258) in the laparoscopy group and $128 \mathrm{~min}$ (range 117-149) in the laparotomy group $(\mathrm{p}=0.05)$. In their study, Renaud et al (17) reported that the operative time was 270 min (range 180-360) in laparoscopically assisted radical vaginal hysterectomy, whereas Spirtos et al (18) found the operative time to be $205 \mathrm{~min}$. Recently, Puntambekar et al (19) reported that the operation time for laparoscopy has been reduced to $92 \mathrm{~min}$ (range 65-120). A standardized, reproducible procedure and a well-trained and skilled surgeon, together with a competent team, using open surgical techniques, should contribute towards this relatively challenging procedure.

Postoperative immune dysfunction is a factor for patients undergoing surgery for benign as well as malignant tumors as it affects the rate of infectious complications as well as the growth of disseminated tumor cells (20). Particularly in patients with cancer, better preserved postoperative immunity may result in more favorable long-term oncological results. It was previously reported that the systemic immune response was better preserved after laparoscopic surgery as compared to after conventional surgery (21-22). The acute-phase response is a favorable indicator of tissue injury in patients (23). Cytokines such as IL-6 and CRP are short-lived, and previous studies have shown elevated serum levels after infection, inflammation and trauma. Serum levels were found to peak 4 to $48 \mathrm{~h}$ after injury.

IL-6 is significant in trauma research as studies have shown that the increase in circulating IL-6 serum levels is almost proportional to the severity of surgery trauma. Moreover, IL-6 release may be used to evaluate the impact of injury in the early stages regardless of the injury pattern (24-26). In recent years, more research has been conducted on other surgical procedures and their impact on the immune system (27). Based on these results, this prospective clinical study was conducted to address the issue of potential differences in postoperative immunological alterations after laparoscopic and open surgery. The maximum increase of IL- 6 in serum was found 1 day after the operation in the two groups, followed by a decline after 4 days. In contrast to certain studies in which no significant change was found in the CRP concentration between females undergoing laparoscopically assisted vaginal hysterectomy and those undergoing abdominal hysterectomy (28), we verified that there was a significantly less severe increase in serum IL-6 levels after laparoscopic cervical surgery. Our data are in accordance with those of previous studies (29-30), which reported that the serum concentration of IL-6 and CRP is significantly different in the laparoscopy and conventional surgery groups.

IL-6 is known to stimulate numerous immune cells and the synthesis of acute-phase proteins, including CRP. CRP is the prototypical acute-phase protein in humans and is a significant mediator of immune host defense (24-26). Normal baseline levels of circulating CRP are low, but a many-fold increase may occur within hours of inflammation induced by infection or injury (29). Serum CRP levels are elevated as a result of major surgery, but have not always reflected the magnitude of acute trauma after open and laparoscopic surgery since CRP is a non-specific marker of an acute-phase reaction (31). Compared to the serum IL-6 levels, the maximum increase was delayed by 2 days in the two groups. However, the increase in serum CRP levels was found to be significantly less pronounced 1,4 and 7 days after surgery in the laparoscopy group as compared to the laparotomy group, indicating a certain benefit for the minimally invasive procedure.

Cortisol is a glucocorticoid produced by the adrenal cortex in response to adrenocorticotropic hormone (ACTH). Cortisol is secreted with a circadian periodicity and peaks just prior to waking in the morning. The production of glucocorticoids 
is increased by stress; therefore, cortisol can be used as a biomarker of stress. Serum levels of cortisol were measured 1, 4 and 7 days after the operation. The daily comparison showed a significantly higher increase after open surgery, particularly at 4 days after surgery, suggesting that serum cortisol elastase levels reflect the body's stress after surgery, thereby indicating less pronounced tissue injury after laparoscopic cervical cancer treatment.

The difference in increase of IL-6, CRP and cortisol serum levels between the two groups may correlate to the difference in tissue trauma and surgical stress caused by the two different methods. However, the immune response may be caused by the underlying pathology. All of the patients in our study had cervical cancer, and the increase in IL-6, $\mathrm{CRP}$ and cortisol was equal, thus appearing to be independent of the underlying pathology. Although these substances are short-lived, their effect is believed to be much more sustained. However, their role in inflammation has yet to be thoroughly clarified.

From our study, it can be deduced that there is a significant decrease in surgical trauma in the laparoscopy group compared to the conventional open surgery group, especially on days 1 and 4 . The significant differences between laparoscopic and conventional colorectal surgery patients regarding the release of CRP and IL-6 suggest a more pronounced proinflammatory response in patients undergoing conventional surgery. This observation confirms findings reported by Leung et al (32), who detected significantly smaller peaks of circulating IL-1 $\beta$, IL-6, and CRP levels in a group of 34 patients undergoing laparoscopic or conventional resection of rectosigmoid carcinoma. It is not clear whether these differences are immunologically relevant since a certain degree of proinflammation is required for the initiation of host defense mechanisms as well as for the activation of repair processes after tissue trauma (33-34). It is nonetheless accepted that an overwhelming inflammatory response to surgical trauma may ultimately lead to organ dysfunction (35).

Findings of our study as well as previous ones, have demonstrated that serum IL-6, CRP and cortisol can be used to monitor surgical trauma. By using these parameters, the surgical trauma after laparoscopic surgery was found to be significantly reduced compared to that observed following the open procedure. After more than 20 years of research, a laparoscopically assisted vaginal radical hysterectomy can safely be performed and is comparable in terms of side effects, complications and patient trauma. This procedure not only involves less blood loss and a shorter postoperative hospital stay, but also less surgical stress. The rapid development of endoscopy and skillful operation of the surgeon and the fact that patients usually prefer surgery with better cosmetic results, laparoscopy is likely to become widely used. Consistent with the results of other studies, the results of this study demonstrated improved clinical recovery with laparoscopy, which was of benefit to the patients.

However, any form of radical hysterectomy; both laparoscopically assisted vaginal hystectomy and laparotomy, which are traumatic involves significant trauma and leads to an acute-phase response. Therefore, operations should be carried out carefully at every step in order for minimally invasive surgery to be less traumatic for patients.

\section{Acknowledgements}

This study was supported in part by grant D09050703570903 (to Yuan-Qing Yao).

\section{References}

1. Querleu D, Leblanc E and Castelain B: Laparoscopic pelvic lymphadenectomy in the staging of early carcinoma in the cervix. Am J Obstet Gynecol 164: 579-581, 1991.

2. Dargent D and Mathevet P: Radical laparoscopic vaginal hysterectomy. J Gynecol Obstet Biol Reprod 21: 709-710, 1992.

3. Querleu D: Laparoscopically assisted radical vaginal hysterectomy. Gynecol Oncol 51: 248-254, 1993.

4. Roy M: Laparoscopically assisted vaginal radical hysterectomy. Best Pract Res Clin Obstet Gynaecol 19: 377-86, 2005.

5. Morgan DJ, Hunter DC, McCracken G, et al: Is laparoscopically assisted radical vaginal hysterectomy for cervical carcinoma safe? A case control study with follow up. BJOG 114: 537-542, 2007.

6. Jackson KS, Das N, Naik R, et al: Laparoscopically assisted radical vaginal hysterectomy vs. radical abdominal hysterectomy for cervical cancer: a match controlled study. Gynecol Oncol 95: 655-61, 2004

7. Steed H, Rosen B, Murphy J, et al: A comparison of laparascopic-assisted radical vaginal hysterectomy and radical abdominal hysterectomy in the treatment of cervical cancer. Gynecol Oncol 93: 588-593, 2004.

8. Malur S, Possover $\mathrm{M}$ and Schneider A: Laparoscopically assisted radical vaginal versus radical abdominal hysterectomy type II in patients with cervical cancer. Surg Endosc 15: 289-292, 2001.

9. Sharma R, Bailey J, Anderson R, et al: Laparoscopically assisted radical vaginal hysterectomy (Coelio-Schauta): A comparison with open Wertheim/Meigs hysterectomy. Int J Gynecol Cancer 16: 1927-1932, 2006.

10. Nam JH, Kim JH, Kim DY, et al: Comparative study of laparoscopico-vaginal radical hysterectomy and abdominalradical hysterectomy in patients with early cervical cancer. Gynecol Oncol 92: 277-283, 2004.

11. Kohler C, Klemm P, Schau A, et al: Introduction of transperitoneal lymphadenectomy in a gynecologic oncology center: analysis of 650 laparoscopic pelvic and/or paraaortic transperitoneal lymphadenectomies. Gynecol Oncol 95: 52-61, 2004.

12. Hertel H, Kohler C, Michels W, et al: Laparoscopic-assisted radical vaginal hysterectomy (LARVH): prospective evaluation of 200 patients with cervical cancer. Gynecol Oncol 90: 505-511, 2003.

13. Lee CL, Huang KG, Jain S, et al: Comparison of laparoscopic and conventional surgery in the treatment of early cervical cancer. J Am Assoc Gynecol Laparosc 9: 481-487, 2002.

14. Dargent D and Mathevet P: Schauta's vaginal hysterectomy combined with laparoscopic lymphadenectomy. Baillieres Clin Obstet Gynaecol 9: 691-705, 1995.

15. Allendorf JDF, Bessler M, Kayton ML, Oesterling SD, Tret MR, Nowygrod R and Whelan RL: Increased tumor establishment and growth after laparotomy vs laparoscopy in a murine model. Arch Surg 130: 649-653, 1995.

16. Mutter D, Hajri A, Tassetti V, Solis-Caxaj C, Aprahamian M and Marescaux J: Increased tumor growth and spread after laparoscopy vs laparotomy. Surg Endosc 13: 365-370, 1999.

17. Renaud MC, Plante M and Roy M: Combined laparoscopic and vaginal radical surgery in cervical cancer. Gynecol Oncol 79: 59-63, 2000.

18. Spirtos NM, Eisenkop SM, Schlaerth JB, et al: Laparoscopic radical hysterectomy (type III) with aortic and pelvic lymphadenectomy in patients with stage I cervical cancer: surgical morbidity and intermediate follow-up. Am J Obstet Gynecol 187: 340-348, 2002.

19. Puntambekar SP, Palep RJ, Puntambekar SS, et al: Laparoscopic total radical hysterectomy by the Pune technique: our experience of 248 cases. J Minim Invasive Gynecol 14: 682-689, 2007.

20. Salo M: Effects of anaesthesia and surgery on the immune response. Acta Anaesthesiol Scand 36: 201-220, 1992.

21. Bolla G and Tuzzato G: Immunologic postoperative competence after laparoscopy vs laparotomy. Surg Endosc 17: 1247-1250, 2003. 
22. Gupta A and Watson DI: Effect of laparoscopy on immune function. Br J Surg 88: 1296-1306, 2001.

23. Lennard TW, Shenton BK, Borzotta A, et al: The influence of surgical operations on components of the human immune system. Br J Surg 72: 771-776, 1985.

24. Cruickshank AM, Fraser WD, Burns HJ, van Damme J and Shenkin A: Response of serum interleukin-6 in patients undergoing elective surgery of varying severity. Clin Sci 79: 161-165, 1990.

25. Gebhard F, Pfetsch H, Steinbach G, et al: Is interleukin 6 an early marker of injury severity following major trauma in humans? Arch Surg 135: 291-295, 2000.

26. Stensballe J, Christiansen M, Tonnesen E, et al: The early IL-6 and IL-10 response in trauma is correlated with injury severity and mortality. Acta Anaesthesiol Scand 53: 515-521, 2009.

27. Holub Z: Impact of laparoscopic surgery on immune function. Clin Exp Obstret Gynecol 29: 77-81, 2002.

28. Harkki-Siren P, Sjoberg J, Toivonen J and Tiitinen A: Clinical outcome and tissue trauma after laparoscopic and abdominal hysterectomy: a randomized controlled study. Acta Obstet Gynecol Scand 79: 866-871, 2000.
29. Malik E, Buchweitz O, Muller-Steinhardt M, et al: Prospective evaluation of the systemic immune response following abdominal, vaginal, and laparoscopically assisted vaginal hysterectomy. Surg Endosc 15: 463-466, 2001.

30. Yuen PM, Mak TW, Yim SF, Kee WD, et al: Metabolic and inflammatory responses after laparoscopic and abdominal hysterectomy. Am J Obstet Gynecol 179: 1-5, 1998.

31. Baigrie RJ, Lamont PM, Kwiatkowski D, et al: Systemic cytokine response after major surgery. Br J Surg 79: 757-760, 2000.

32. Leung KL, Lai PB, Ho RL, et al: Systemic cytokine response after laparoscopic-assisted resection of rectosigmoid carcinoma: a prospective randomized trial. Ann Surg 231: 506-511, 2000.

33. Jeschke MG, Wolf SE, DebRoy MA and Herndon DN: The combination of growth hormone with hepatocyte growth factors alters the acute phase response. Shock 12: 181-187, 1999.

34. Gabay C and Kushner I: Acute-phase proteins and other systemic responses to inflammation. N Engl J Med 340: 448-454, 1999.

35. Faist $\mathrm{E}$ and Wichmann MW: Immunology in the severely injured. Chirurg 68: 1066-1070, 1997. 